\title{
Adherence with American Academy of Pediatrics guidelines when managing neonatal jaundice in Jordan
}

This article was published in the following Dove Press journal:

Research and Reports in Neonatology

20 April 2013

Number of times this article has been viewed

\author{
Mohammad Khassawneh' \\ Ziad Rubaie ${ }^{2}$ \\ Issa Khashashneh ${ }^{3}$ \\ Fakhri Makhlouf ${ }^{4}$ \\ Ahmed Alkafajei ${ }^{2}$ \\ 'Department of Pediatrics, \\ ${ }^{2}$ Department of Public Health, \\ Jordan University of Science \\ and Technology; ${ }^{3}$ Department \\ of Pediatrics, Prince Rashid \\ Hospital; ${ }^{4}$ Department of Pediatrics, \\ Princess Rahma Children's \\ Hospital, Irbid, Jordan
}

Background: Bilirubin encephalopathy is a significant health problem in developing countries. Understanding regional practices in comparison with international standards is needed to assess the safety and efficacy of our local management practice.

Methods: This retrospective study included all neonates ( $\geq 35$ weeks gestation) with hyperbilirubinemia who were admitted to the three main neonatal units in northern Jordan between January 2007 and January 2009. Demographic variables and risk factors were collected. Management of hyperbilirubinemia in the absence of national guidelines was compared with that recommended by the American Academy of Pediatrics.

Results: Four hundred and sixteen infants were admitted with hyperbilirubinemia and received phototherapy. The phototherapy threshold was met in only $210(50 \%)$ of infants. Seventy infants $(17 \%)$ received exchange transfusion, and the threshold was met in $60(86 \%)$ infants. Only $50 \%$ of infants who needed exchange transfusion received the procedure.

Conclusion: Despite the high rate of unnecessary phototherapy, exchange transfusion was performed in one of every two infants who met the international criteria for the procedure. Studies are needed in our country to evaluate the impact of this practice on infants with hyperbilirubinemia.

Keywords: neonatal jaundice, hyperbilirubinemia, exchange transfusion, guidelines

\section{Introduction}

Neonatal jaundice and its complications still represent a major health challenge in many developing countries, and contribute to both neonatal mortality and morbidity. ${ }^{1,2}$ A recent report from Egypt reported that bilirubin encephalopathy occurred in 14\% of infants with severe hyperbilirubinemia. ${ }^{3}$ There are no national practical guidelines for management of neonatal jaundice in Jordan. Treatment of this problem is not standardized, and may vary from one institution to another and from one physician to another. The American Academy of Pediatrics (AAP) in 1994 agreed on guidelines for the management of neonatal jaundice in healthy term infants. ${ }^{4}$ In 2004 , an update of these guidelines was issued that included healthy, at-risk, and near-term infants. ${ }^{5}$ Few studies have addressed the impact of the AAP guidelines on the management of neonatal jaundice. ${ }^{6-8}$ However, there is evidence showing decreased admission and readmission rates in neonates with jaundice, as well as a decrease in use of exchange transfusion. ${ }^{9}$

In Jordan, there is little published literature describing neonatal jaundice and its management. ${ }^{10} \mathrm{Abu}$-Ekteish et al reported the rate of exchange transfusion over a 6-year period to be $0.46 \%$, with an annual reduction noticed in the exchange transfusion rate. ${ }^{11}$ 
Although national guidelines do not exist, many pediatricians rely on the graphs included in the AAP guidelines to decide on the need for phototherapy or exchange transfusion. However, use of these procedures in neonates with jaundice is not well studied or standardized. Evaluation of adherence with AAP guidelines by pediatricians and neonatologists in Jordan should shed light on current practices in the management of this problem in a developing country outside the US.

This study describes the incidence and risk factors for significant neonatal jaundice, and predictors of use of exchange transfusion in treatment of the disease in the north of Jordan. The level of agreement between local management of significant neonatal jaundice and the recommendations made in the AAP guidelines in 2004 is also assessed.

\section{Materials and methods}

Three main neonatal intensive care unit (NICU) facilities in the north of Jordan were included in this study. One is the main unit of the only military hospital in the north of Jordan, another is part of the main Ministry of Health children's referral hospital, and the other is part of a tertiary university referral hospital. These hospitals cover all health care sectors in the north of Jordan and are where almost all local exchange transfusions are done. This retrospective study included all neonates who were $\geq 35$ weeks' gestation, weighed $\geq 2000$ g, and were admitted to any of these three main referral centers for treatment of neonatal jaundice. Cases admitted were identified from the database of each hospital for the period between January 1, 2007 and January 1, 2009.

Data were collected by reviewing medical records and completing a structured data sheet that included all independent variables that might have contributed to the development of severe hyperbilirubinemia. A trained research assistant extracted the relevant data from medical records. The data sheet included information for gender, gestational age ( $<38$ weeks or $\geq 38$ weeks), birth weight ( $\leq 2500 \mathrm{~g}$ or $>2500 \mathrm{~g}$ ), family history of neonatal jaundice (in a previous sibling), type of feeding (exclusive breastfeeding or otherwise), whether the newborn was admitted from an infant nursery or from home, or was referred from another hospital, age of the newborn at presentation in hours, maternal blood group (type O or non-type O), ABO incompatibility, Rhesus factor (Rh) incompatibility, glucose6-phosphate dehydrogenase deficiency, Coombs test result, sepsis, other hemolytic diseases, clinical status on admission (considered abnormal if there was decreased activity or a neurological finding), presence of urinary tract infection, cephalohematoma on physical examination, and whether the infant had received intravenous immunoglobulin. Data concerning treatment used, such as phototherapy or exchange transfusion, were also obtained. ABO and $\mathrm{Rh}$ incompatibility were considered to be present when the difference between mother and infant blood groups in a jaundiced infant is a setup of blood group incompatibility.

Using data on risk factors, each case included was classified as low, medium, or high risk according to the 2004 AAP guidelines for treatment of neonatal jaundice. Each case was plotted on the 2004 AAP neonatal jaundice graphs showing risk groups and the corresponding treatment recommendations. These plots were used to compare what the infants received as treatment and what they should have received if the AAP guidelines were followed.

The data were analyzed using the SPSS15.0 software program (SPSS Inc, Chicago, IL, USA). Descriptive data are presented as number of cases, percent, mean, and standard deviation. The statistical relationship ( $P$ value) of the independent variables was analyzed using the Chi-square test. $P<0.05$ was considered to be statistically significant.

\section{Results}

A total of 416 neonates hospitalized with hyperbilirubinemia were identified for this study, and included 177 (42.5\%) newborns from King Abdullah University Hospital, 148 (35.6\%) from Princess Rahma Teaching Hospital, and 91 (21.9\%) from Prince Rashid Teaching Hospital. In total, 273 neonates (65.8\%) were admitted straight from home, 124 (29.9\%) were admitted from an infant nursery, and 18 (4.3\%) were referred from other hospitals.

According to Jordan statistics for 2007 and 2008, there were about 55,000 births in Irbid within the two-year period of the study. ${ }^{12}$ An estimated 76 neonates were admitted with jaundice for every 10,000 births $(0.76 \%)$, and the proportion needing exchange transfusion was $0.13 \%$ during the study period. The proportion of neonates with a peak total serum bilirubin level $\geq 20 \mathrm{mg} / \mathrm{dL}$ would be one in 355 births ( 155 in $55,000)$ and one in 948 births with a peak total serum bilirubin level $\geq 25 \mathrm{mg} / \mathrm{dL}$ (58 in 55,000) over the two-year study period. ABO incompatibility was found in 183 (44.68\%) patients and $\mathrm{Rh}$ incompatibility in 41 (10\%). Forty-four (14.1\%) patients were reported to have glucose-6-phosphate dehydrogenase deficiency.

The characteristics of the subjects included in this study are shown in Table 1. Table 2 shows use of exchange transfusion according to different patient characteristics and risk factors, as well as infants who exceeded the AAP threshold for exchange transfusion according to risk factors. 
Table I Characteristics of hospitalized newborns with hyperbilirubinemia included in the study

\begin{tabular}{llllll}
\hline Characteristics & Sample & Minimum & Maximum & Mean & SD \\
\hline Gestational age (weeks) & 416 & 35 & 41 & 39.02 & 1.71 \\
Birth weight (g) & 407 & 2000 & 5200 & 3041.30 & 535.36 \\
Age at presentation (hours) & 416 & $\mathrm{I}$ & 384 & 87.34 & 69.77 \\
Bilirubin level at presentation (mg/dL) & 416 & 3.0 & 45.0 & 16.76 & 6.8588 \\
PCV at presentation (\%) & 398 & 20.0 & 73.0 & 46.47 & 7.96 \\
Duration of stay in hospital (days) & 412 & $\mathrm{I}$ & 22 & 4.44 \\
\hline
\end{tabular}

Abbreviations: PCV, packed cell volume; SD, standard deviation.

All neonates with hyperbilirubinemia admitted to a NICU received phototherapy. According to the AAP guideline graph, only 210 (50.5\%) newborns met the AAP guideline criterion for phototherapy. Only $70(16.8 \%)$ underwent exchange transfusion, despite the fact that 123 (29.5\%) met the AAP guideline criterion for exchange transfusion. Analysis of the data shows that the majority (85.7\%) of newborns treated with exchange transfusion met the AAP criterion for exchange transfusion $(P<0.001)$.

Only 10 of the 70 patients (14.3\%) who received exchange transfusion did not meet the AAP criterion for exchange transfusion. Five of these neonates had a total serum bilirubin level $>20 \mathrm{mg} / \mathrm{dL}$. In five infants, the exchange transfusion level was total serum bilirubin $<20 \mathrm{mg} / \mathrm{dL}$, but they were found to have a rapid rise in levels after exchange transfusion. One neonate with $\mathrm{Rh}$ isoimmunization underwent exchange transfusion shortly after birth at a bilirubin level of $6.4 \mathrm{mg} / \mathrm{dL}$, but the reasons for this were not explained in the patient's medical records.

\section{Discussion}

This study describes the level of adherence in Jordan with the 2004 AAP guideline for treatment of significant neonatal hyperbilirubinemia. The results of this study show that half of all patients admitted with neonatal jaundice did not reach the threshold level for phototherapy recommended by the AAP guideline. Most newborns who underwent exchange transfusion met the relevant criteria. However, about one in every six cases underwent exchange transfusion without reaching the threshold level recommended by the AAP, indicating nonadherence with the guidelines and indicate more concern for bilirubin-induced neurotoxicity among Jordanian doctors. Ten patients underwent exchange transfusion without reaching the threshold, suggesting that many Jordanian pediatricians are more liberal in the use of exchange transfusion. One infant with $\mathrm{Rh}$ incompatibility underwent exchange transfusion at a bilirubin level $<7 \mathrm{mg}$ / $\mathrm{dL}$, but his medical record did not explain the reason for this. The rate of exchange transfusion in this study is about $30 \%$ lower than that described in Jordan more than 10 years ago. This may reflect early detection of hyperbilirubinemia, more awareness of risk factors, and better follow-up of high-risk cases. A more liberal approach to severe hyperbilirubinemia has been reported by a large pediatric group in the US. Newman et al described the outcomes for 140 newborns with total serum bilirubin levels $>25 \mathrm{mg} / \mathrm{dL}$, where exchange transfusion was only undertaken in five cases. That study reported similar developmental outcomes in neonates with severe hyperbilirubinemia and in controls without jaundice. ${ }^{9}$

Approximately half of the newborns identified by this study did exceed the threshold for exchange transfusion were treated only with phototherapy. Flaherman et al evaluated infants in the setting of universal screening for hyperbilirubinemia and found that only one of 22 infants who exceeded the AAP threshold actually received exchange transfusion. ${ }^{13}$ In a cross-sectional study of adherence with the 1994 AAP guidelines, Atkinson et al showed that phototherapy was administered to only half of the neonates who met the AAP guideline recommendations for phototherapy, and only $0.2 \%$ of infants who did not meet the threshold received phototherapy. ${ }^{14}$ Manning et al, when reporting on 102 infants with severe hyperbilirubinemia (total serum bilirubin $>30 \mathrm{mg} / \mathrm{dL}$ ) in the UK and Ireland, showed that only 48 infants (less than 50\%) received exchange transfusion and only 14 showed evidence of bilirubin neurotoxicity. ${ }^{15}$

In our study, 58 infants had a bilirubin level $>25 \mathrm{mg} / \mathrm{dL}$ and 39 (about two thirds) received exchange transfusion, suggesting that we are more liberal in our use of this treatment than Western centers. In this study, $27.5 \%$ of children with abnormal findings on presentation underwent exchange transfusion, while $14 \%$ with a normal examination underwent exchange transfusion. Salas et al recently described outcomes in infants with severe hyperbilirubinemia treated with exchange transfusion, and concluded that all those presenting with signs of advanced bilirubin encephalopathy went on to have permanent neurological deficits. ${ }^{16}$ Similar findings were reported by Johnson et al from a pilot registry study of kernicterus in the US. ${ }^{17}$ The retrospective nature of 
Table 2 Characteristics of neonates hospitalized with hyperbilirubinemia and treated by exchange transfusion who met the American Academy of Pediatrics criterion for exchange transfusion by univariate analysis

\begin{tabular}{|c|c|c|c|c|c|c|c|}
\hline \multirow[t]{2}{*}{ Variable } & \multirow[t]{2}{*}{ Sample } & \multicolumn{3}{|c|}{$\begin{array}{l}\text { Treatment using exchange } \\
\text { transfusion }\end{array}$} & \multicolumn{3}{|c|}{$\begin{array}{l}\text { Met AAP criteria for exchange } \\
\text { transfusion }\end{array}$} \\
\hline & & $\begin{array}{l}\text { Yes } \\
\text { n (\%) }\end{array}$ & $\begin{array}{l}\text { No } \\
\text { n (\%) }\end{array}$ & $P$ value* & $\begin{array}{l}\text { Yes } \\
\text { n (\%) }\end{array}$ & $\begin{array}{l}\text { No } \\
\text { n (\%) }\end{array}$ & $P$ value* \\
\hline \multicolumn{8}{|c|}{ Gestational age (weeks) } \\
\hline $35-37$ & 84 & $14(16.7)$ & $70(83.3)$ & 0.965 & $31(36.9)$ & $53(63.1)$ & 0.099 \\
\hline$\geq 38$ & 323 & $56(16.9)$ & $276(83.1)$ & & $92(27.7)$ & $240(72.3)$ & \\
\hline$>2500$ & 342 & $61(17.8)$ & $28 \mid(82.2)$ & & $96(28.1)$ & $246(71.9)$ & \\
\hline \multicolumn{8}{|l|}{ Family history of $\mathrm{NJ}$} \\
\hline Yes & 150 & $36(24)$ & $114(76)$ & 0.003 & $59(39.3)$ & $91(60.7)$ & 0.001 \\
\hline No & 266 & $34(12.8)$ & $232(87)$ & & $64(24.1)$ & $202(75.9)$ & \\
\hline Others & 284 & $45(15.8)$ & $239(84.2)$ & & $85(29.9)$ & $199(70.1)$ & \\
\hline \multicolumn{8}{|c|}{ Admission to neonatal care unit from } \\
\hline Newborn nursery & 124 & II (8.9) & $113(91.1)$ & 0.006 & $24(19.4)$ & $100(80.6)$ & 0.007 \\
\hline Home & 273 & $53(19.4)$ & $220(80.6)$ & & $91(33.3)$ & $182(66.7)$ & \\
\hline Other hospital & 18 & $6(33.3)$ & $12(66.7)$ & & $8(44.4)$ & $10(55.6)$ & \\
\hline \multicolumn{8}{|c|}{ Age at presentation (hours) } \\
\hline$\leq 24$ & 117 & $17(14.5)$ & $100(85.5)$ & 0.721 & $29(24.8)$ & $88(75.2)$ & 0.408 \\
\hline $25-119$ & 160 & $29(18.1)$ & $|3|(8 \mid .9)$ & & $50(31.2)$ & $110(68.8)$ & \\
\hline$\geq 120$ & 139 & $24(17.3)$ & $115(82.7)$ & & $44(31.7)$ & $59(68.3)$ & \\
\hline \multicolumn{8}{|c|}{ Peak bilirubin level (mg/dL) } \\
\hline$<20$ & 261 & $9(3.4)$ & $252(96.6)$ & $<0.001$ & $28(10.7)$ & $233(89.3)$ & $<0.001$ \\
\hline $20-24.9$ & 97 & $22(22.7)$ & $75(77.3)$ & & $37(38.1)$ & $60(61.9)$ & \\
\hline$\geq 25$ & 58 & $39(67.2)$ & $19(32.8)$ & & $58(100)$ & $0(0)$ & \\
\hline \multicolumn{8}{|l|}{ PCV at presentation } \\
\hline$<35$ & 21 & $7(33.3)$ & $14(66.7)$ & 0.042 & $8(38.1)$ & $13(61.9)$ & 0.399 \\
\hline$\geq 35$ & 377 & $61(16.2)$ & $316(83.8)$ & & III (29.4) & $266(70.6)$ & \\
\hline$<25$ & 70 & $7(10)$ & $63(90)$ & & $19(27.1)$ & $51(72.9)$ & \\
\hline \multicolumn{8}{|l|}{$A B O$ incompatibility } \\
\hline Yes & 183 & $32(17.5)$ & $|5|(82.5)$ & 0.749 & $57(31.1)$ & $126(68.9)$ & 0.580 \\
\hline No & 227 & $37(16.3)$ & $190(83.7)$ & & $65(28.6)$ & 162 (7I.4) & \\
\hline \multicolumn{8}{|l|}{ Rh incompatibility } \\
\hline Yes & 41 & $8(19.5)$ & $33(80.5)$ & 0.628 & $12(29.3)$ & $29(70.7)$ & 0.943 \\
\hline No & 369 & $61(16.5)$ & $308(83.5)$ & & $110(29.8)$ & $259(70.2)$ & \\
\hline \multicolumn{8}{|l|}{ G6PD } \\
\hline Normal & 269 & $40(14.9)$ & $229(85.1)$ & 0.187 & $67(24.9)$ & $202(75.1)$ & 0.110 \\
\hline Low & 44 & $10(22.7)$ & $34(77.3)$ & & $16(36.4)$ & $28(63.6)$ & \\
\hline \multicolumn{8}{|l|}{ Direct Coombs test } \\
\hline Positive & 53 & $8(15.1)$ & $45(84.9)$ & 0.787 & $13(24.5)$ & $40(75.5)$ & 0.463 \\
\hline Negative & 350 & $58(16.6)$ & $292(83.4)$ & & $103(29.4)$ & $247(70.6)$ & \\
\hline \multicolumn{8}{|l|}{ Sepsis } \\
\hline Yes & 24 & $8(33.3)$ & $16(66.7)$ & 0.026 & $13(54.2)$ & II (45.8) & 0.007 \\
\hline No & 392 & $62(15.8)$ & $330(84.2)$ & & $110(28.1)$ & $282(71.9)$ & \\
\hline \multicolumn{8}{|l|}{ Clinical examination } \\
\hline Normal & 336 & $48(14.3)$ & $288(85.7)$ & 0.005 & $93(27.7)$ & $243(72.3)$ & 0.084 \\
\hline Abnormal & 80 & $22(27.5)$ & $58(72.5)$ & & $30(37.5)$ & $50(62.5)$ & \\
\hline \multicolumn{8}{|l|}{ IVIG treatment } \\
\hline Yes & 25 & $4(16)$ & $21(84)$ & 0.909 & $9(36)$ & $16(64)$ & 0.467 \\
\hline No & 391 & $66(16.9)$ & $325(83.1)$ & & $114(29.2)$ & $277(70.8)$ & \\
\hline
\end{tabular}

Note: $* P$ value of the Chi-square test statistic.

Abbreviations: AAP, American Academy of Pediatrics; IVIG, intravenous immunoglobulin; NJ, neonatal jaundice; G6PD, glucose-6-phosphate dehydrogenase; PCV, packed cell volume.

our study did not allow for accurate follow-up of infants with an abnormal clinical examination, and further research on bilirubin encephalopathy is needed to understand the magnitude of this problem. One important and significant risk factor for hyperbilirubinemia requiring exchange transfusion in our study was admission from home or transfer from other hospital. Inadequate risk assessment and poor follow-up of neonates with significant risk factors have been shown to be the main reasons for late presentation with severe hyperbilirubinemia. ${ }^{18,19}$ Lack of home visiting and late 
presentation of severe hyperbilirubinemia after discharge to home may justify the liberal approach of pediatric physicians in Jordan when admitting and treating jaundiced infants with lower bilirubin levels.

\section{Conclusion}

Health care providers in Jordan are more liberal in admitting infants with jaundice for phototherapy. Exchange transfusion is often done in infants without meeting the threshold for such an invasive procedure. Referral from outside hospital and higher bilirubin level were the best predictors of use of exchange transfusion. Future studies on outcomes in patients with severe hyperbilirubinemia are needed to evaluate the safety and efficacy of our practice in preventing the complications of severe hyperbilirubinemia.

\section{Disclosure}

The authors report no conflicts of interest in this work.

\section{References}

1. Olusanya BO, Ezeaka CV, Ajayi-Obe EK, Mukhtar-Yola M, Ofovwe GE. Paediatricians' perspectives on global health priorities for newborn care in a developing country: a national survey from Nigeria. BMC Int Health Hum Rights. 2012;12(1):9.

2. Iliyasu Z, Abubakar IS, Gajida AU. Magnitude and leading causes of in-hospital mortality at Aminu Kano Teaching Hospital, Kano, northern Nigeria: a 4-year prospective analysis. Niger J Med. 2010; 19(4):400-406.

3. Gamaleldin R, Iskander I, Seoud I, et al. Risk factors for neurotoxicity in newborns with severe neonatal hyperbilirubinemia. Pediatrics. 2011;128(4):e925-e931.

4. American Academy of Pediatrics, Provisional Committee for Quality Improvement and Subcommittee on Hyperbilirubinemia. Practice parameter: management of hyperbilirubinemia in the healthy term newborn. Pediatrics. 1994;94(4 Pt 1):558-565.

5. American Academy of Pediatrics, Subcommittee on Hyperbilirubinemia. Management of hyperbilirubinemia in the newborn infant 35 or more weeks of gestation. Pediatrics. 2004;114(1):297-316.
6. Seidman DS, Paz I, Armon Y, Ergaz Z, Stevenson DK, Gale R. Effect of publication of the "Practice Parameter for the management of hyperbilirubinemia" on treatment of neonatal jaundice. Acta Paediatr. 2001;90(3):292-295.

7. Kuzniewicz MW, Escobar GJ, Newman TB. Impact of universal bilirubin screening on severe hyperbilirubinemia and phototherapy use. Pediatrics. 2009;124(4):1031-1039.

8. Alkalay AL, Bresee CJ, Simmons CF. Decreased neonatal jaundice readmission rate after implementing hyperbilirubinemia guidelines and universal screening for bilirubin. Clin Pediatr (Phila). 2010; 49(9):830-833.

9. Newman TB, Liljestrand P, Jeremy RJ, et al; Jaundice and Infant Feeding Study Team. Outcomes among newborns with total serum bilirubin levels of $25 \mathrm{mg}$ per deciliter or more. $N$ Engl J Med. 2006;354(18):1889-1900.

10. Khassawneh M, Khader Y, Amarin Z, Al Sa'd S, Alkafajei A. Traditional practices for newborns: the north of Jordan perspective. JMJ. 2008; 42(4):211-219.

11. Abu-Ekteish F, Daoud A, Rimawi H, Kakish K, Abu-Heija A. Neonatal exchange transfusion: a Jordanian experience. Ann Trop Paediatr. 2000;20(1):57-60.

12. Ministry of Health Statistics in Jordan. Census and crude birth rates of years 2007 and 2008. Available from: http://www.moh.gov.jo.

13. Flaherman VJ, Kuzniewicz MW, Escobar GJ, Newman TB. Total serum bilirubin exceeding exchange transfusion thresholds in the setting of universal screening. J Pediatr. 2012;160(5):796-800.

14. Atkinson LR, Escobar GJ, Takayama JI, Newman TB. Phototherapy use in jaundiced newborns in a large managed care organization: do clinicians adhere to the guideline? Pediatrics. 2003;111(5 Pt 1): e555-e561.

15. Manning D, Todd P, Maxwell M, Jane Platt M. Prospective surveillance study of severe hyperbilirubinaemia in the newborn in the UK and Ireland. Arch Dis Child Fetal Neonatal Ed. 2007;92(5):F342-F346.

16. Salas AA, Mazzi E. Exchange transfusion in infants with extreme hyperbilirubinemia: an experience from a developing country. Acta Paediatr. 2008;97(6):754-758.

17. Johnson L, Bhutani VK, Karp K, Sivieri EM, Shapiro SM. Clinical report from the pilot USA Kernicterus Registry (1992 to 2004). J Perinatol. 2009;29 Suppl 1:S25-S45.

18. Maisels MJ. Risk assessment and follow-up are the keys to preventing severe hyperbilirubinemia. J Pediatr (Rio J). 2011;87(4):275-276.

19. Punaro E, Mezzacappa MA, Facchini FP. Systematic follow-up of hyperbilirubinemia in neonates with a gestational age of 35 to 37 weeks. J Pediatr (Rio J). 2011;87(4):301-306.

Research and Reports in Neonatology

\section{Publish your work in this journal}

Research and Reports in Neonatology is an international, peer-reviewed, open access journal publishing original research, reports, editorials, reviews and commentaries on neonatal health. The manuscript management system is completely online and includes a very quick and fair

peer-review system. Visit http://www.dovepress.com/testimonials.php to read real quotes from published authors. 